\title{
Archaeoastronomical Aspects of the Archaeological Monuments of Siberia
}

\section{Leonid Marsadolov}

\begin{abstract}
The necessity of astronomical observations for nomadic peoples of Eurasia was based on the sacral meaning of time. The celestial bodies, the Sun and the Moon were parts of cult of the Sky. During annual migrations, in particular those where there were no reliable landmarks, nomads navigated with the North Star and the main constellations of the night sky. Remains left by these nomads, including rock pictures, barrows and observation posts are the legacy of a complex, organised system reflecting the relations of ancient people with the cosmos.
\end{abstract}

\section{Introduction}

From 1987 to 2010 the Sayan-Altai archaeological expedition of The State Hermitage Museum conducted palaeoastronomical research studies on the different sanctuaries of Central Asia and Southern Siberia in Russia. ${ }^{1}$ The ancient Altai sanctuaries represent an original type of nomadic cult. They have been studied periodically since the eighteenth century. In spite of the fact that there is now a body of research into cult archaeological sites in this region, the recognition of their sacral functions is still not well understood. Three aspects should be singled out for the interpretation of ancient cult objects:

1. The real material aspect includes comprehensive information about the material remains and artefacts of a site.

\footnotetext{
${ }^{1}$ Leonid S. Marsadolov, 'Salbyk barrow in Khakasia (Russia, Siberia)', in European Association of Archaeologists 5th Annual Meeting, Final Programme and Abstracts, Bournemouth, United Kingdom 14th-19th September 1999 (Bournemouth: Bournemouth University Press, 1999): pp. 91-92; Leonid S. Marsadolov, 'New semantics of the barrow Arzhan', in 6th Annual Meeting European Association of Archaeologists Final Programme and Abstracts (Lisbon: Lisbon University Press, 2000): pp. 82-83; Leonid S. Marsadolov, 'Lights and Shadows in the Culture of Central Asia's Peoples', in Lights and Shadows in Cultural Astronomy, Proceedings of the SEAC 2005, Isili, Sardinia, 28 June to 3 July (Isili, 2007): pp. 279-88.
}

Leonid Marsadolov, 'Archaeoastronomical Aspects of the Archaeological Monuments of Siberia', eds. Nicholas Campion and Rolf Sinclair, Culture and Cosmos, Vol. 16 nos. 1 and 2, 2012, pp. 109-117.

www.CultureAndCosmos.org 
110 Archaeoastronomical Aspects of the Archaeological Monuments of Siberia

2. The ancient scientific aspect refers to fixed general and special regularities: a) mathematical, geometrical, astronomical, technological and landscape; b) search and reconstruction of the main metrical relationships between objects or different parts of a site's construction; c) research into the possible existence of astronomically significant directions.

3. The sacral aspect includes a) cult functions and shapes of the objects erected at particular times and places; b) these objects' location in the landscape; c) the wide use of 'oppositions' for construction of the objects, for example: top part - low part, eastwest, mountain - low ground; d) complex systems of relationship between different types of objects; and e) the existence of special 'roads' connecting objects which often go outside the boundaries of a site.

As a result, it is necessary to use a variety of methods. Figures 1 and 2 show regional distinctions in orientation of barrows and people.

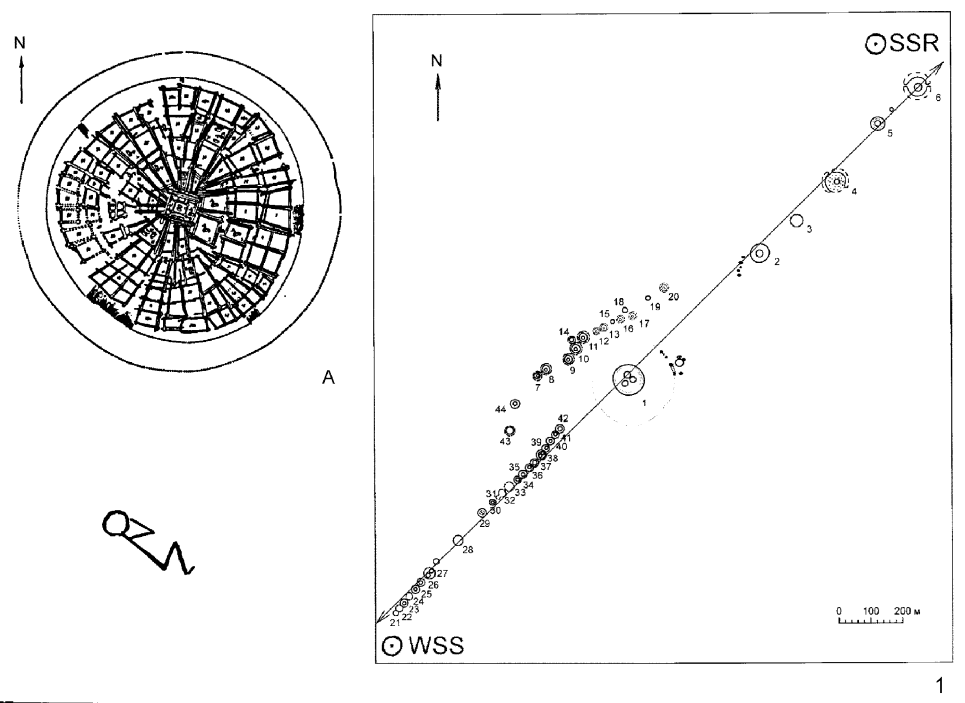

Figure 1. In Tuva, Central Asia, the barrow Arzhan-1 (A) and burial ground Arzhan-II, a "chain" of barrows showing the orientation to the rising and setting of the Sun on astronomically significant days. Abbreviations: SSR summer solstice sunrise; WSS -winter solstice sunset, N - north. 


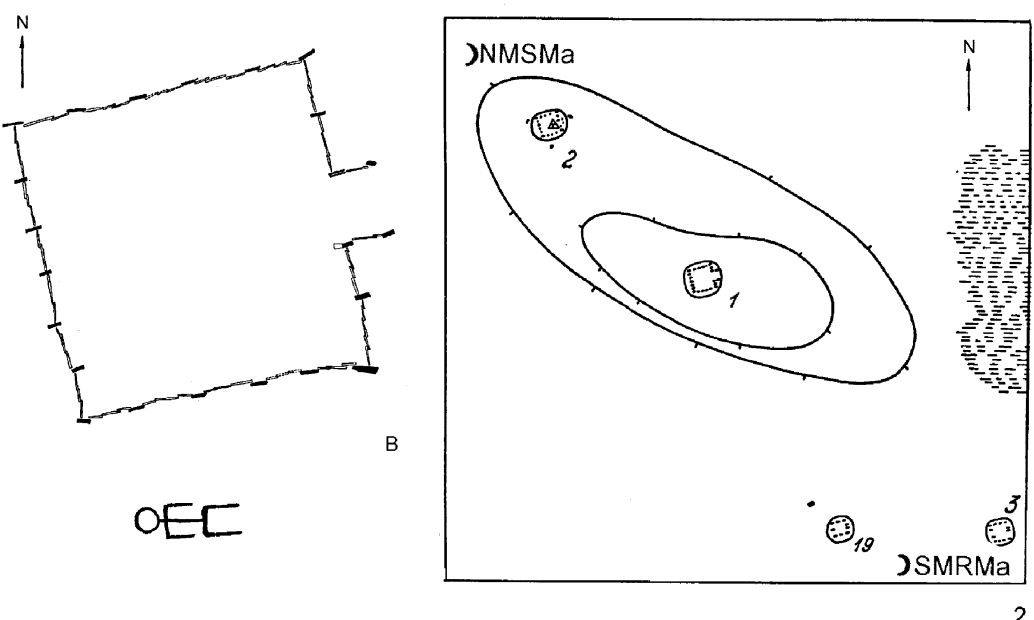

Figure 2. The Great Salbyk Barrow in the Salbyk Valley in Khakasia, Siberia; barrow Salbyk (B) and burial ground in Salbyk (on right) with the "chain" of barrows, from barrows 1-2 and barrows 1-3, showing the orientation to Moonrise and Moonset on the astronomically significant days. Abbreviations: $\mathrm{N}$-north; NMSMa - northern moonset, major standstill; SMRMa - southern moonrise, major standstill.

\section{Arzhan}

From 1971 to 1974, archaeological expeditions under the direction of M.H. Mannai-Ool and M.P. Griaznov excavated the barrow Arzhan-1: the largest barrow of Sayan-Altai, situated near the settlement of Arzhan in Tuva. ${ }^{2}$ (Figure 1:A) This burial mound was chosen as the most suitable for study from geographical and astronomical points of view: it is located in the center of Turan-Uyuk valley, which stretches in a west-to-east direction. The highest mountains in this region are situated to the north and south of this barrow by a comparatively small distance, but the east and west sides have low, far-removed mountains, allowing one to observe the risings and settings of the Moon and the Sun throughout the whole year. Some correlation was found between the directions of burial-mound "rays" on the one hand and mountain tops and depressions, situated along

2 M.P. Griaznov, Arzhan - the tsar barrow of the Early Scythian period (Leningrad: Nauka, 1980) [in Russian]. 
112 Archaeoastronomical Aspects of the Archaeological Monuments of Siberia

astronomically significant points of equinoxes and solstices, on the other hand.

The barrow Arzhan is not only a complex funeralcommemorative object, it is also a model of the world of the ancient nomads of Central Asia. The tripartite vertical structure can be seen in the burial-mound clearly enough: the upper world is the stone embankment, the middle world (burials of people and horses) is of wooden design and the lower world is the ground. It has a tetra/octahedral structure as well, with four sectors on the main cardinal points (North, South, East, West) and four intermediate sectors between those points. It is possible to link an eastern sector of the burial mound with the spring, while other sectors are linked with other seasons of the year counterclockwise: the North represents summer, the West represents autumn and the South, winter.

The chieftain of an alliance of nomad tribes, his wife (or concubine) and eight persons were buried in the central part of the burialmound Arzhan. In addition, burials in the north-eastern part (two persons) and south-western parts (four persons) of the burial-mound may be explained by their location at the points of astronomically significant days. The numbers of horses buried in separate chambers in the burialmound Arzhan probably also reflect a certain symbolism. Only the following numbers occur twice: two (referring to oppositions such as rise-set, day-night, spring-autumn etc.), seven (a lunar phase week) and 30 (one month). The largest number of buried horses lies in the eastern part of the mound: $30+30+15+3+12=90$ horses $=3$ months. About 160 horses and 15 to 20 tails of horses were buried under the floor of the central chamber. This barrow was erected in the August-September time frame, as deduced by dendro-chronological analysis. So, it is possible that the nomads of Sayan-Altai in the end of the eighth century BCE counted the days per annum beginning from the first day of the vernal equinox.

The barrow at Arzhan is one of the earliest, but not the only monument in the Eurasian steppes, where the idea was realized that one horse may be equivalent in time to one day or one year. This idea is also reflected in the total number of buried horses in the mounds of Kuban, excavated by $\mathrm{N}$. Veselovsky in 1898 (the relevant reports are still unpublished): 360 horses $=1$ year and 30 horses $=1$ month.

Salbyk

The Great Salbyk Barrow is the best known of the megalithic monuments in Siberia. Archaeologist S.V. Kiselev excavated the Salbyk Barrow, the 
largest in Khakasia, from 1954 to 56 (Figure 2). ${ }^{3}$ The expedition of the State Hermitage Museum researched Salbyk Valley from 1992 to 1998, in 2008 and $2010 .^{4}$ A point for the barrow centre was chosen very carefully in the mountain valley. The point had to satisfy certain requirements:

1. It had to be on the highest place between mountains;

2. It had to be surrounded by mountains lower to the west and east than to the north and south;

3. It had to be conveniently situated for astronomical observations.

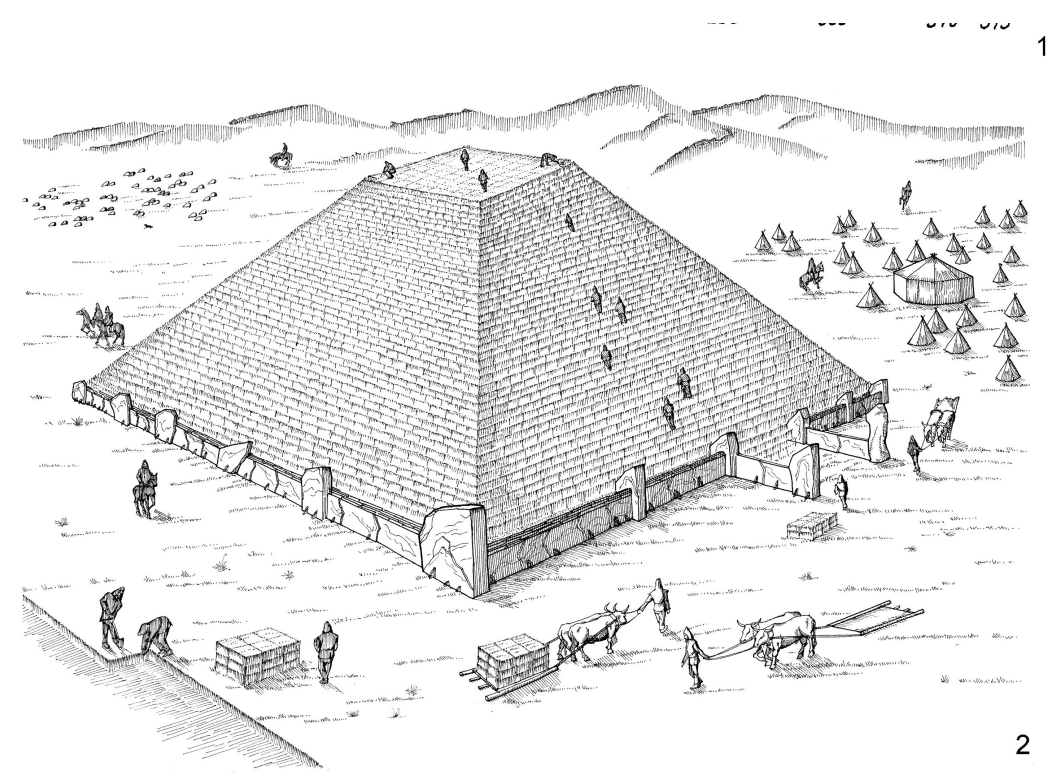

Figure 3. Reconstruction of the Great Salbyk Barrow

It should be mentioned that such a place was found in an earlier period and kept its meaning in later epochs. There is the Bronze Age ritual centre with stone sculpture of the Okunevskaya culture, and sites of the

\footnotetext{
${ }^{3}$ S. V. Kiselev Research of the Big Salbyk barrow in 1954 and 1955, in Theses of reports at session of the Office of Historical Sciences and Plenum of Institute of History of Material Culture devoted to results of archaeological researches of 1955. (Moscow, 1956), pp. 56-58 [in Russian].

${ }^{4}$ Leonid S. Marsadolov, Big Salbyk barrow in Khakasia. (Abakan, 2010). p. 128 [in Russian].
} 
114 Archaeoastronomical Aspects of the Archaeological Monuments of Siberia

Early Tagar period near the Great Salbyk barrow. The barrow has a height of more than 20 metres and is pyramid-shaped (Figure 3). A square "fence" ( 71 x 71 metres) under the mound was made of huge stone slabs, which were placed vertically and horizontally and weighed some tonnes (the average size was about 5 metres). Installation of fence slabs is connected with the main positions of the rising and setting of the moon and sun on astronomically significant days (Figure 4).
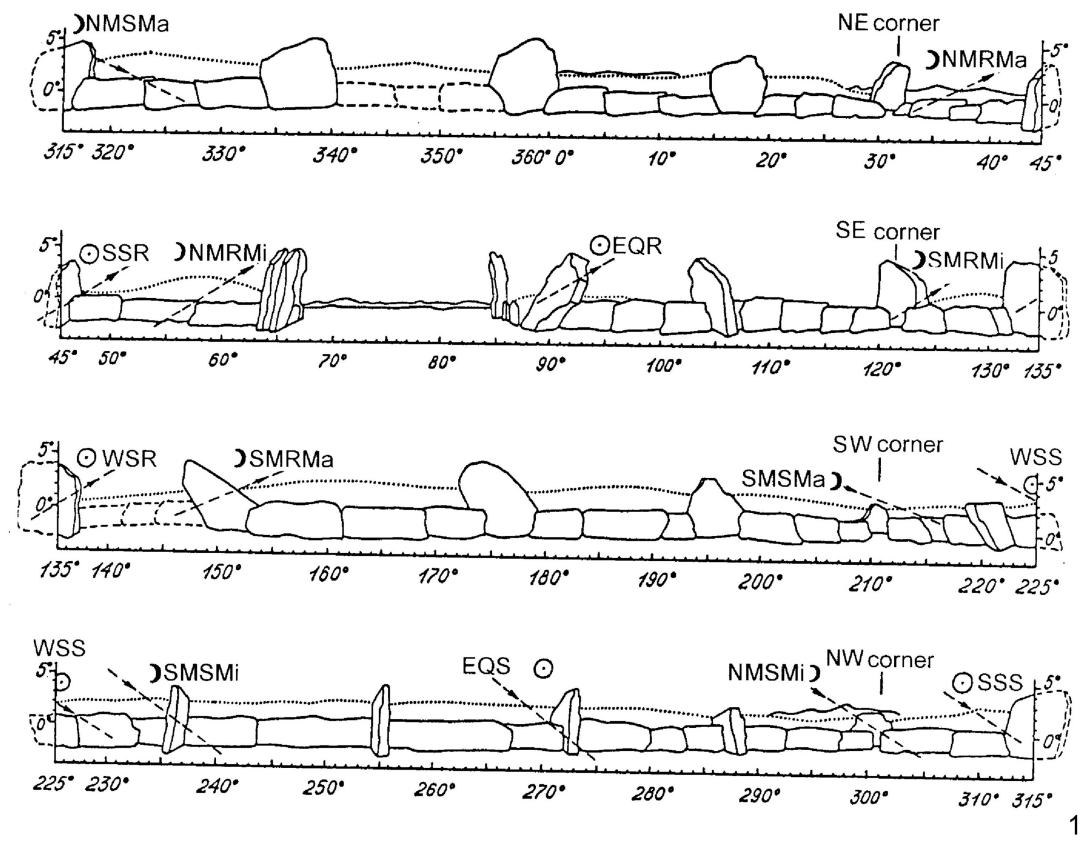

Figure 4. Salbyk (Khakasia, $7^{\text {th }}$ century B.C.), showing the rising and setting of the Moon and Sun on astronomically significant days. Abbreviations: SSR - Summer Solstice Sunrise; SSS - Summer Solstice Sunset; WSR = Winter Solstice Sunrise; WSS - Winter Solstice Sunset; EQR - Equinox Sunrise; EQS - Equinox Sunset. N - North; S - South; MS - Moonset; MR - Moonrise; Ma - Major standstill; Mi - Minor standstill: NMRMa - Northern Moonrise, Major standstill; NMSMa Northern Moonset, Major standstill; NMRMi - Northern Moonrise, Minor standstill; NMSMi - Northern Moonset, Minor standstill; SMRMa Southern Moonrise, Major standstill; SMSMa - Southern Moonset, Major standstill; SMRMi - Southern Moonrise, Minor standstill; SMSMi Southern Moonset, Minor standstill. 
The burial construction consisted of three parts: a corridor (dromos), an extension near a door, and a burial chamber. In the central part of the barrow, but closer to western wall of the fence, a structure consisting of earth and logs was found. It looked like a reduced pyramid; its height was about 2 metres and its upper platform was $8 \times 8$ metres. The pyramid was at first sight white as snow because its slopes were covered with a thick layer of birch bark (sometimes fifteen layers).

The entrance from the barrow's eastern side was rather complex. From the two middle steles, the long slabs were perpendicular to the line of the wall, resting on two steles of 5 metres high placed towards the east. From the eastern side, "the entrance" between the steles was covered with a roof of small slabs which were placed very carefully, with a small deviation inside the barrow.

There was a square pit measuring $5 \times 5$ metres and 1.8 metres deep under the pyramid. Its walls were lined with vertical logs. The chamber was 4 x 4 metres; its height was about 2 metres. It was covered by six rows of massive logs with a thick layer of birch bark. The bottom of the framework and the space between its walls and the logs covering the pit's walls were full of solid, red, water-resistant clay. S.V. Kiselev established that the bottom was covered with birch bark under the clay. ${ }^{5}$

The remnants of seven men and women were found in the chamber. An old warrior was buried in the centre, some of whose bones were broken. A large clay vessel was found in fragments. Near the middle part of the western wall of the framework, on the bottom, a miniature bronze knife was also found.

The temporary wooden fencing was replaced by a permanent fencing from stone plates in Salbyk. Some of great barrows have "chains" of vertically standing slabs as well as horizontally placed "slab-altars" near the mound. Outside the barrow were found vertical stones of intermediate size, aligned to astronomically significant directions.

A sculptural representation of a reclining tiger was also found (Figure 5). A detailed study of the stone slabs of the fence revealed the significance of a colour spectrum - from light to dark tones and back to light.

On one of the slabs from the barrow, a complicated composition is drawn. In the higher part of the slab, the sky is represented: a bird, the sun, stars, and a person with a crozier in his hand. In the middle part of the slab, a male warrior stands with a foot on the head of a fallen person;

\footnotetext{
${ }^{5}$ Kiselev, Research, p. 57 [in Russian].
} 
116 Archaeoastronomical Aspects of the Archaeological Monuments of Siberia

nearby is a moon-woman and also a man. In the lower part of the slab, there are unclear figures of perhaps a horse and a beast. It is possible that on this slab the sequence of the funeral ritual is represented, which corresponds to the archaeological material from the excavations.

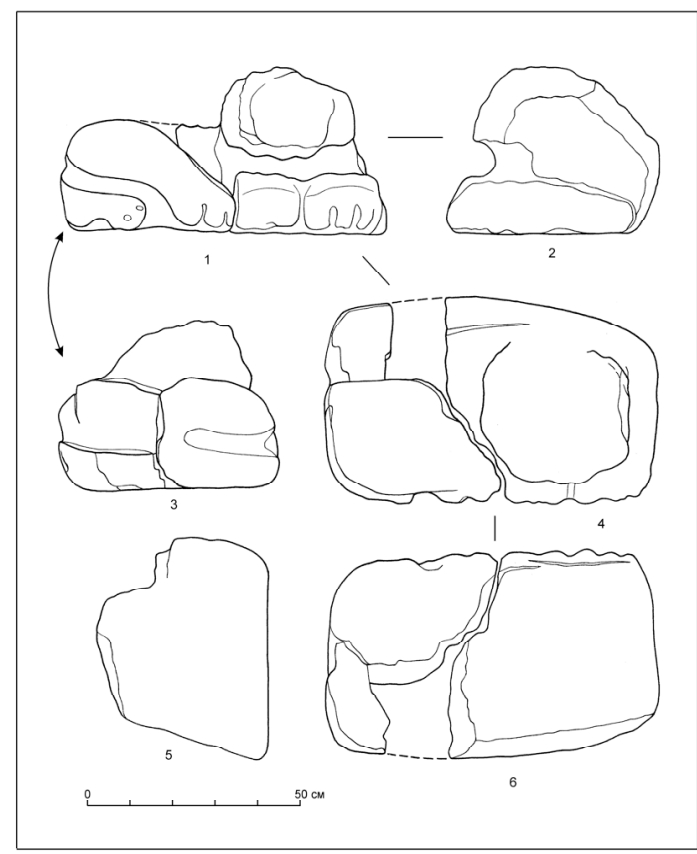

Figure 5. Salbyk. The stone sculpture as a reclining tiger: 1 - front view; 2, 3, 5 - side views; 4 - top view; 6 - bottom view. The sculpture was found by S. Marsadolov in 1996 near the barrow Salbyk

The construction of big barrows in Salbyk with multiple functions (funeral, socio-political, religious, astronomical, architectural, and others) probably was based on the astronomical knowledge of their time. The barrow is dated to the seventh century BCE on basis of new radiocarbon C-14 analyses. The "chain" of barrows in the Salbyk valley is oriented on a line running northwest to southeast, the line of the extreme positions for moonrise and moonset (Figure 2:2). The location of barrows in Salbyk is principally distinguished from the orientation of barrows behind the Sayan range.

Near the Arzhan settlement in Tuva, the great barrows (sixth to fifth centuries BCE) were erected on a line running northeast to southwest and orientated to the sun: specifically to the high point of sunrise on the day of the summer solstice and the low point of sunset on the day of the winter solstice (Figure 1). Thereby, the orientation of the 
barrow's chains serves the important additional (religious) criterion for two previously-chosen large areas of Siberian archaeological monuments.

\section{Conclusion}

Although the written sources did not preserve for us the information about the cult centers, customs and masters of Central Asia in the first millennium BCE, our descendants instead received as their legacy objects: the complex cult constructions. The nomads of Sayan-Altai had burial mounds but, possibly, they had also permanent observation posts which were used as sanctuaries and ritual centers. The correlations of various "rays" and mutual directions of barrows with horizon elements were absent in most cases. There were no artificial marks on the horizon that could testify to really systematic measuring of the Moon or the Sun cycles. However, these barrows have very suitable positions for rise/set observations of various sky objects. 